\title{
Anemia correction by erythropoietin reduces BNP levels, hospitalization rate, and NYHA class in patients with cardio-renal anemia syndrome
}

\author{
Alberto Palazzuoli · Ilaria Quatrini • Anna Calabrò • \\ Giovanni Antonelli • Maria Caputo • Maria S. Campagna • \\ Beatrice Franci • Ranuccio Nuti
}

Received: 14 March 2010/Accepted: 22 April 2010/Published online: 29 May 2010

(C) Springer-Verlag 2010

\begin{abstract}
Little is known about the effect of anemia correction with erythropoietin (EPO) on B-type natriuretic peptide (BNP) levels, NYHA class, and hospitalization rate. The aim of the study was to investigate, in patients with cardio-renal anemia syndrome, the effects of EPO on hemochrome and renal function parameters and BNP levels. We also analyzed the effect of EPO therapy on hospitalization rate and NYHA class after 12 months in comparison with a population undergoing to standard therapy. We performed a randomized double-blind controlled study of correction of the anemia with subcutaneous $\alpha$ (group A $n=13$ ) or $\beta$ (group B $n=14$ ) EPO for 12 months in addition to standard therapy with oral iron in 27 subjects. Control group ( $n=25$ patients) received only oral iron. Significant increase in hemoglobin $(\mathrm{Hb})$, hematocrit (Hct), and red blood cells (RBC) were revealed in $\mathrm{EPO}$ groups at 12 months; $\mathrm{Hb}$, group A $12.3 \pm 0.6$; group B $11.7 \pm 0.8$; control group $10.6 \pm 0.5 \mathrm{~g} / \mathrm{dl}$ $P<0.0001$; Hct group A $34.2 \pm 2.3$, group B $34 \pm 2$, control group $32.3 \pm 1.8 \% \quad P<0.01$; RBC, group A $3.9 \pm 0.2$, group B $3.8 \pm 0.2$, control group $3.3 \pm 0.2$, $(P<0.0001)$. Plasma BNP levels in EPO groups were significantly reduced after 12 months (group A: $335 \pm 138$ vs. group B: $449 \pm 274 \mathrm{pg} / \mathrm{ml}$ control group $582 \pm$ $209 \mathrm{pg} / \mathrm{ml}(P<0.01)$. After 12 months of treatment, hospitalization rate and NYHA class were reduced in EPO groups with respect to control group $(P<0.05)$. Finally, an inverse correlation was observed between BNP and $\mathrm{Hb}$
\end{abstract}

\footnotetext{
A. Palazzuoli $(\bowtie) \cdot$ I. Quatrini · A. Calabrò · G. Antonelli M. Caputo · M. S. Campagna - B. Franci - R. Nuti Cardiology Section, Department of Internal Medicine and Metabolic Diseases, Le Scotte Hospital, University of Siena, Viale Bracci, 53100 Siena, Italy

e-mail: palazzuoli2@unisi.it
}

levels in EPO Groups $(r=-0.70 P<0.001)$. EPO treatment reduces BNP levels and hospitalization rate in patients with cardio-renal anemia syndrome. The correction of anemia by EPO treatment appears able to improve clinical outcome in this subset of patients with heart failure.

Keywords Anemia - Erythropoietin - Heart failure . B-type natriuretic peptide $\cdot$ Cardio-renal syndrome

\section{Introduction}

Anemia is a clinical manifestation commonly observed in patients with congestive heart failure (CHF) and renal disease [1-9]. Prevalence of this condition is estimated to be between 15 and 55\%, depending on the clinical definition of anemia. The prevalence of anemia has been found to be greater in those with older age, more advanced New York Heart Association (NYHA) classes, diabetes, more severe systolic dysfunction, more reduced exercise tolerance, and more reduced renal function [1-9]. Anemia in patients with $\mathrm{CHF}$ is often associated with a more adverse outcome including increased mortality, morbidity, and hospitalization [1-9]. It is known that anemia alone, even without the presence of CHF, can increase heart rate and cardiac output, and cause increased levels of renin, angiotensin, aldosterone, antidiuretic hormone, sympathetic activity and Natriuretic Peptides, reduce renal blood flow, and glomerular filtration rate and increase plasma and interstitial volume [10]. However, it is still not certain whether the anemia in CHF is actually causing the increase in adverse effects or is merely an innocent bystander, a marker for other causes such as inflammation with increased cytokines and/or renal failure [1-10]. 
Erythropoietin (EPO) is a glycoprotein growth factor produced by the kidney. In CHF, treatment with recombinant human EPO increased the hemoglobin $(\mathrm{Hb})$ concentration and improved many aspects of $\mathrm{CHF}$ including functional status and quality of life [11-20]. However, most of interventional studies conducted in patients with $\mathrm{CHF}$ and anemia that showed an improvement in exercise tolerance and in functional status were uncontrolled studies [11] or controlled studies but without a placebo [12-20]. In the present study, we extend the previous studies by investigating the effects of subcutaneous (sc) EPO and oral iron versus oral iron alone on laboratory parameters, BNP levels, and on clinical outcome (hospitalization rate and NYHA classes) during one-year follow-up period.

\section{Materials and methods}

\section{Patient population}

The starting patients number consisted in 80 subjects with a history of moderate to severe CHF (NYHA Class III or IV), mild to moderate renal insufficiency with $\mathrm{CrCl}$ between 60 and $30 \mathrm{ml} / \mathrm{min}$, and anemia (defined as $\mathrm{Hb}$ levels below $11.5 \mathrm{~g} / \mathrm{dl}$ on two occasions separated by 1-2 weeks). Before the enrollment, all patients underwent optimized medical treatment for $\mathrm{CHF}$, according to the last ESC guidelines [21]. The study population was homogenous for exercise tolerance, co-morbidities, laboratory investigations, and echocardiographic examination.

\section{Exclusion criteria}

Patients with isolated diastolic dysfunction, more than moderate valvular disease, recent myocardial infarction (within 12 weeks), modifiable causes of anemia, severe renal failure, and gastrointestinal bleeding were excluded. All patients undergoing fecal occult blood tests, if it was positive, were also excluded.

\section{Study protocol: double-blind period}

Group A, consisting of 13 patients, was treated with subcutaneous (sc) $\alpha$-EPO twice weekly and daily oral iron as a ferrous gluconate $300 \mathrm{mg}$ tablet.

Group B, consisting of 14 patients, was treated with subcutaneous (sc) $\beta$-EPO twice weekly and daily oral iron as a ferrous gluconate $300 \mathrm{mg}$ tablet. Control group (25 patients) received the oral iron alone and sc saline injections twice weekly.

The EPO and saline injections were similar and it was impossible to know which syringes the patients received. The physicians were unaware which syringes they used.
The dose of EPO was 6,000 international units (IU). The EPO or placebo were done twice weekly for 12 months. All patients referred to our ambulatories for standard clinical checkups, as before the study, on the basis of their clinical status. If any adverse effect or treatment was manifested during follow-up, this was immediately interrupted. Both groups were re-evaluated for the study at 12 months from onset of experimental protocol.

\section{Laboratory analysis}

A complete blood count with $\mathrm{Hb}$, Hct, red blood cell (RBC) count, RBC indices, serum creatinine sodium, and potassium were performed at baseline and after 12 months of treatment. Creatinine clearance was estimated from the serum creatinine values using the Cockroft-Gault formula [22]. Plasma BNP was measured at the beginning and at the end of the study, using the quantitative immunofluorescence assay manufactured by Biosite (San Diego, CA, USA). The analytic sensitivity of the assay is $<5 \mathrm{pg} / \mathrm{ml}$ and the upper normal limit is considered to be $100 \mathrm{pg} / \mathrm{ml}$.

Primary and secondary end points

Primary end points assessed were laboratory data including $\mathrm{Hb}$, hematocrit (Hct), red blood cells (RBC), and creatinine clearance; these parameters were evaluated at the start and at the end of the 12-month study period. BNP modifications were evaluated at the beginning and after 12 months. For each patient, NYHA class was obtained at baseline and at 12 months of follow-up. Secondary end points that were monitored included sudden death, hospitalizations, and myocardial infarction.

\section{Statistical analysis}

Continuous data were expressed as mean \pm SD. The data were analyzed for statistically significant differences by ANOVA/ANCOVA test for unpaired data and by linear correlation using the SPSS 17 for Windows (SPSS Inc, Chicago IL). The significant level was set at $P<0.05$. Results were considered significant if there was, within or between group analyses, a statistical confidence level of $95 \%$.

\section{Results}

Of the 80 consecutively recruited patients, only 56 had inclusion criteria. Of these, 2 refused to continue the study protocol and 2 needed blood transfusions to correct their anemia. Four patients died during the follow-up period ( 3 in control group and 1 in EPO groups). Thus, only 48 
patients completed the follow-up study. During the 12 months follow-up, no adverse effects due to the treatment were reported. Thirty patients were in NYHA class III and 22 were in class IV. General and clinical characteristics of the study population are summarized in Table 1.

Significant increase in hemoglobin $(\mathrm{Hb})$, hematocrit (Hct), and red blood cells (RBC) was revealed in EPO groups at 12 months $(\mathrm{Hb}$, group A: $10.4 \pm 0.6 \mathrm{~g} / \mathrm{dl}$ baseline and $12.3 \pm 0.6 \mathrm{~g} / \mathrm{dl} 12$ months, $P<0.01$; group $\mathrm{B}$ : $9 \pm 3.4 \mathrm{~g} / \mathrm{dl}$ baseline, $11.7 \pm 0.8 \mathrm{~g} / \mathrm{dl} 12$ months $P<0.01$; control group: $10.6 \pm 0.4 \mathrm{~g} / \mathrm{dl}$ baseline $11.9 \pm 0.8 \mathrm{~g} / \mathrm{dl}$ 12 months $P$ ns; Hct, group A: $30 \pm 1.2 \%$ baseline, $34.2 \pm 2.3 \% 12$ months, $P<0.001$; group B: $30.8 \pm$ $1.3 \%$ baseline, $34 \pm 2 \% 12$ months, $P<0,00001$; control group $32 \pm 1.7 \%$ baseline and $34 \pm 2 \%$ at 12 months, $P$ $\mathrm{ns}$; RBC, group A $3.6 \pm 0.7 \mathrm{mil} / \mathrm{mm}^{3}$ baseline, $3.90 \pm 2$ $\mathrm{mil} / \mathrm{mm}^{3} 12$ months $P<0.00001$; group B: $3.2 \pm 0.2$ $\mathrm{mil} / \mathrm{mm}^{3}$ baseline, $3.8 \pm 0.2 \mathrm{mil} / \mathrm{mm}^{3} 12$ months, $P<0.00001$; control group: $3.2 \pm 0.2 \mathrm{mil} / \mathrm{mm}^{3}$ baseline vs. $3.8 \pm 0.2 \mathrm{mil} / \mathrm{mm}^{3}$ at 12 months, $P$ ns). Significant increases in $\mathrm{CrCl}$ were revealed in the study population neither after 12 months of treatment nor between EPO groups with respect to control group. Plasma BNP levels in EPO groups were significantly reduced after 12 months (group A: $512 \pm 127 \mathrm{pg} / \mathrm{ml}$ baseline vs. $335 \pm 138 \mathrm{pg} / \mathrm{ml}$ 12 months $P<0.01$; group B: $659 \pm 321 \mathrm{pg} / \mathrm{ml}$ baseline vs. $449 \pm 274 \mathrm{pg} / \mathrm{ml} 12$ months $P<0.01$ ). No significant difference was found for BNP plasma levels after 12 months in control group $(610 \pm 231$ baseline vs. $582 \pm 209 \mathrm{pg} / \mathrm{ml}, P$ ns) with a significant difference between EPO groups and control groups after12 months of treatment $(405 \pm 235 \mathrm{pg} / \mathrm{ml}$ vs. $582 \pm 209 \mathrm{pg} / \mathrm{ml} P<0.01)$. (Table 2). NYHA class was significantly reduced in EPO groups after 12 months of follow-up (group A: $3.38 \pm 0.5$ baseline vs. $2.7 \pm 0.712$ months, $P<0.05$; group $\mathrm{B}$ : $3.5 \pm 0.5$ baseline vs. $2.78 \pm 0.812$ months, $P<0.01$; control group: $3.32 \pm 0.47$ baseline vs. $3.2 \pm 0.6, P$ ns; $P$ intergroups $<0.01)$ and showed a significant inverse correlation with $\mathrm{Hb}$ levels $(r=-0.45 ; P<0.05$, Fig. 1). Finally, an inverse correlation was observed between BNP and $\mathrm{Hb}$ levels in EPO groups $(r=-0.70, P<0.001$; Fig. 2a, b).
Secondary end points

Four patients died during the year study: 3 in control group ( 1 for sudden death, 2 for refractory CHF) and 1 in EPO groups (from sudden death). After 12 months of treatment, hospitalization rate was significantly reduced in EPO groups with respect to control group (25\% vs. $56 \%$ $P<0.05$, Fig. 3). No significant change in blood pressure, body weight, and myocardial events were seen.

\section{Discussion}

Small clinical trials have shown that the correction of anemia with erythropoietin or its derivatives with oral or intravenous iron treatment has been associated with lower hospitalization rates, better quality of life, improved exercise tolerance, and reduced neuro-hormonal activation and pro-inflammatory cytokine expression [11-19]. Despite these reports, the only large multicenter randomized placebo controlled interventional trial was not able to demonstrate significant clinical benefits with darbepoetin alfa therapy, a long-acting erythropoiesis stimulating agent (ESA) [20]. In the current study, we found the increase in $\mathrm{Hb}, \mathrm{RBC}$, and HCT values lead to NYHA class reduction and BNP level decreases. In this paper, we extend previous published data showing that EPO treatment in patients with CRS anemia leads to reverse ventricular remodeling together with systolic function improvement [18]. All these changes were supported by the fall in BNP that we found in the treated patients: since BNP is one of the most powerful markers of adverse outcomes in CHF, its plasma lowering might indirectly signal an improvement in cardiac function and outcome in patients with CRS in whom the anemia is corrected [23]. Secondary end points also demonstrated significantly reduced hospitalization without any modification in body weight, blood pressure, or other potential adverse effects. Our results appear in contrast with respect to recent clinical trials showing negative or neutral effects of EPO administration in patients with chronic kidney diseases (CKD). However, we need to keep in mind that patients enrolled in the cited studies are quite different: only 23 and $31 \%$ had a
Table 1 Clinical and laboratory characteristics in the treated group (A and B) and control group

\begin{tabular}{llll}
\hline NYHA class & $\begin{array}{l}\text { Group A 13 pz } \\
\text { 8 III/5 IV }\end{array}$ & $\begin{array}{l}\text { Group B 14 pz } \\
\text { 7 III/7 IV }\end{array}$ & $\begin{array}{l}\text { Control group 25 pz } \\
\text { 15 III/10 IV }\end{array}$ \\
\hline Coronary artery disease & 6 & 8 & 12 \\
Hypertension & 7 & 11 & 15 \\
Body mass index $\left(\mathrm{g} / \mathrm{cm}^{2}\right)$ & $27.9 \pm 6$ & $28.1 \pm 1$ & $26.5 \pm 3$ \\
LVEF $(\%)$ & $28.3 \pm 4.3$ & $31.2 \pm 8.4$ & $30.9 \pm 5.9$ \\
Hb concentration $(\mathrm{g} / \mathrm{dl})$ & $10.4 \pm 0.6$ & $9 \pm 3.4$ & $9.3 \pm 3.4$ \\
Creatinine clearance $(\mathrm{ml} / \mathrm{min})$ & $45.8 \pm 5.9$ & $44.2 \pm 6.2$ & $44.8 \pm 5.2$ \\
\hline
\end{tabular}




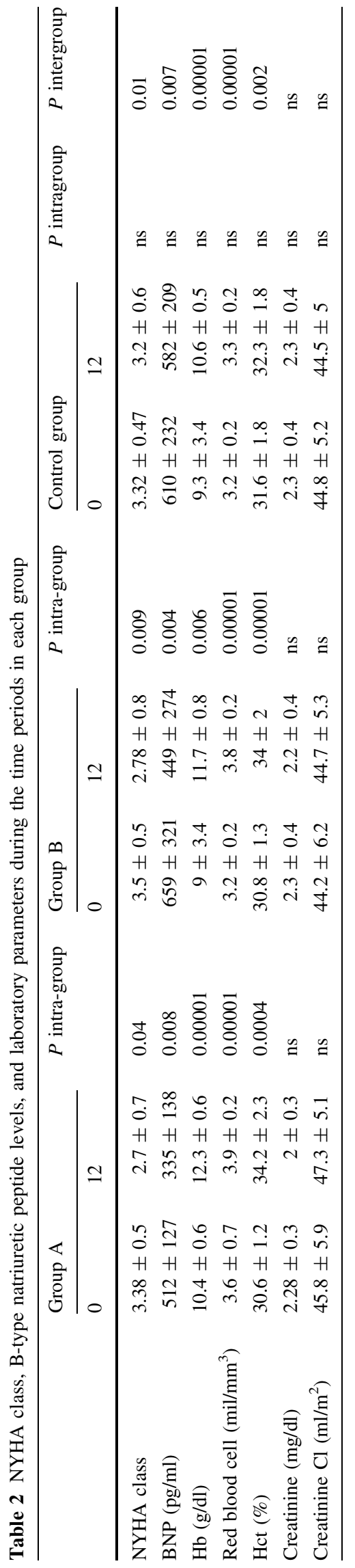

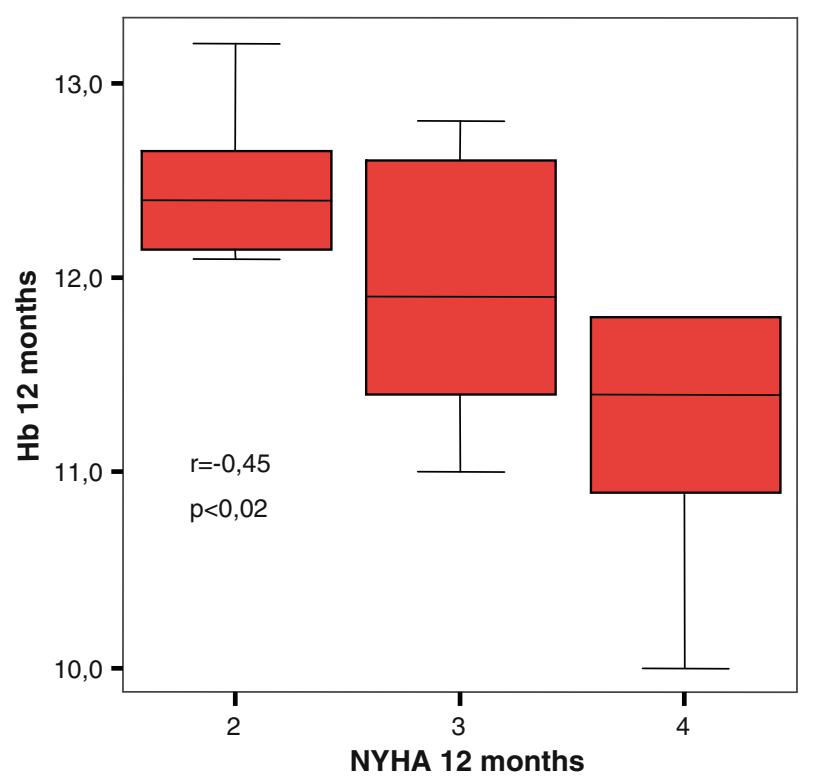

Fig. 1 Correlation between $\mathrm{Hb}$ levels and NYHA class in the EPO groups at the end of the follow-up period

CKD history. Therefore, $\mathrm{Hb}$ target was higher with respect to our study [24-26]. Patients with anemic HF are often affected by primary iron deficiency, for this reasons, all the group included in our study were submitted to oral iron therapy. Recently, Anand et al. demonstrated the pivotal role of iron administration in this context [27].

The effects we saw may be related not only to the EPOinduced correction of anemia and the decrease in volume overloading but also to EPO's cytoprotective properties that lead to a significant increase in cardiac contractile reserve. Recently, an experimental study showed prevention of cardiac remodeling by low doses of EPO treatment independent of hematocrit increase [28]. This is in keeping with other animal studies demonstrating that EPO appears able to directly improve LV function even without increasing the hemoglobin $[29,30]$. EPO can induce myocardial neovascularization and prevent myocardial cell apoptosis, myocardial fibrosis, and oxidative stress in animal models secondary to myocardial infarction, CHF or ischemic injury.

\section{Study limitations}

This single-center study was limited by its small sample size. The investigators were blinded to the EPO medication. Many of the parameters evaluated during follow-up that improved with treatment were objective and could not be easily biased by the investigator. It is likely that the baseline weight of some subjects was above their ideal weight due to fluid retention upon hospital admission. We did not measure all iron parameters and particularly 
Fig. 2 Inverse correlation in controls and in treated patients between hemoglobin and B-type natriuretic peptide (BNP)

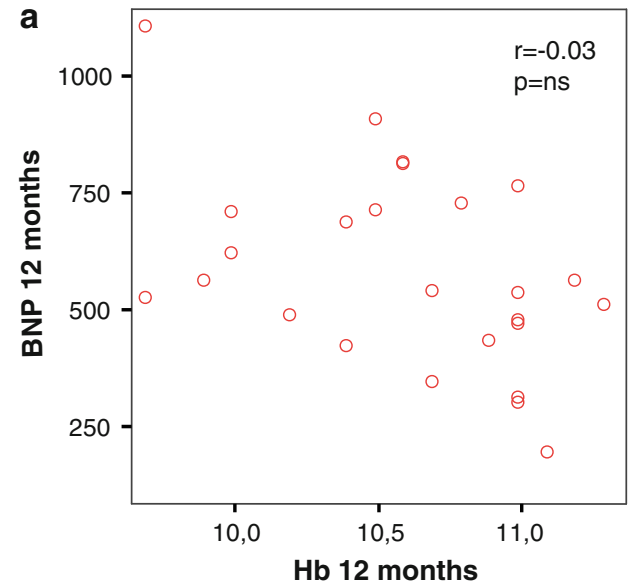

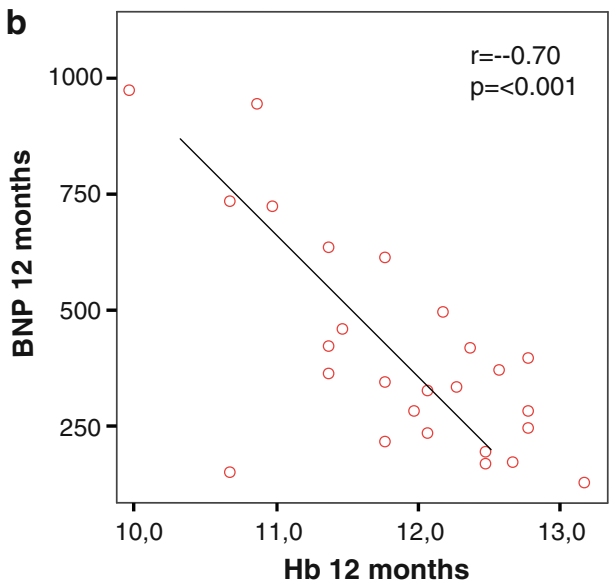

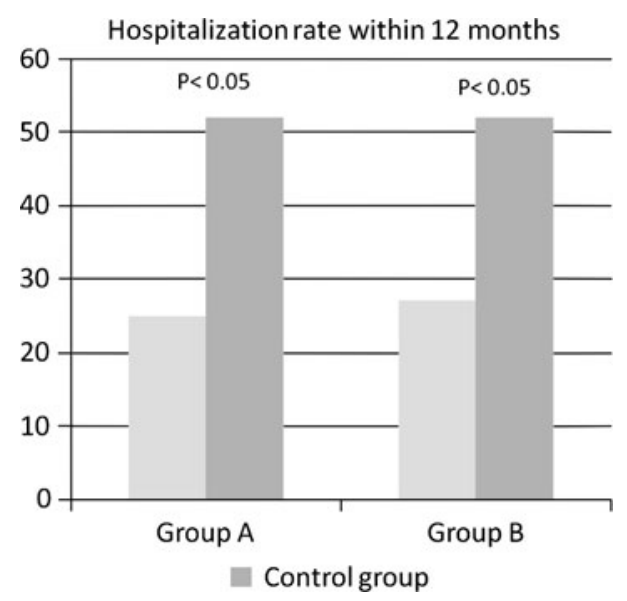

Fig. 3 Hospitalization rate in group A and B with respect to controls during one-year follow-up period

transferrin saturation, even if all patients took oral ferrous gluconate.

\section{Conclusions}

Correction of anemia in patients with CRS leads to an improvement in NYHA class with hospitalization rate reduction. All these positive changes occur together with BNP decrease and appear related to anemic status correction.

Acknowledgments We are grateful to the Roche Italia S.P.A. for the supply of $\beta$-erythropoietin (Neo Recormon) and Jansen-Cilag for the supply of $\alpha$-erythropoietin (Eprex).

Conflict of interest None.

\section{References}

1. Horwich TB, Fonarow GC, Hamilton MA et al (2002) Anemia is associated with worse symptoms, greater impairment in functional capacity and a significant increase in mortality in patients with advanced heart failure. J Am Coll Cardiol 39:1780-1786

2. Mozaffarian D, Nye R, Levy WC (2003) Anemia predicts mortality in severe heart failure: the prospective randomized amlodipine survival evaluation (PRAISE). J Am Coll Cardiol 41:1933-1939

3. Felker GM, Adams KF Jr, Gattis WA, O'Connor CM (2004) Anemia as a risk factor and therapeutic target in heart failure. $\mathrm{J}$ Am Coll Cardiol 44:959-966

4. Ezekowitz JA, McAlister FA, Armstrong PW (2003) Anemia is common in heart failure and is associated with poor outcomes: insights from a cohort of 12065 patients with new-onset heart failure. Circulation 107:223-225

5. Mitchell JE (2007) Emerging role of anemia an heart failure. Am J Cardiol 99:15D-20D

6. Palazzuoli A, Gallotta M, Iovine F, Nuti R, Silverberg DS (2008) Anaemia in heart failure: a common interaction with chronic renal insufficiency called the cardio renal anaemia syndrome. Int J Clin Pract 62:281-286

7. Tang Y-D, Katz S (2008) The prevalence of anemia in chronic heart failure and its impact on the clinical outcomes. Heart Failure Rev 13:387-392

8. Groenveld HF, Januzzi JL, Damman K (2008) Anemia and mortality in heart failure patients: a systematic review and metaanalysis. J Am Coll Cardiol 52:818-827

9. Silverberg DS, Wexler D, Iaina A, Schwartz D (2008) The role of anaemia in patients with congestive heart failure: a short review. Eur J Heart Failure 10:819-823

10. Anand IS (2008) Anemia and chronic heart failure. J Am Coll Cardiol 52:501-511

11. Silverberg DS, Wexler D, Blum M et al (2000) The use of subcutaneous erythropoietin and intravenous iron for the treatment of the anemia of severe, congestive heart failure improves cardiac and renal function, functional cardiac class, and markedly reduces hospitalizations. J Am Coll Cardiol 35:1737-1744

12. Silverberg DS, Wexler D, Sheps D et al (2001) The effect of correction of mild anemia in severe, resistant congestive heart failure using subcutaneous erythropoietin and intravenous iron: a randomized controlled study. J Am Coll Cardiol 37:1775-1780

13. Mancini DM, Katz SD, Lang CC et al (2003) Effect of erythropoietin on exercise capacity in patients with moderate to severe chronic heart failure. Circulation 21:294-299

14. Kourea K, Parissis JT, Farmakis D, Panou F, Paraskevaidis I et al (2008) Effect of darbepoetin-alfa on plasma pro-inflammatory cytokines, anti-inflammatory cytokines interleukin-10 and soluble Fas/fas ligand system in anemic patients with chronic heart failure. Atherosclerosis 199:215-221 
15. Kourea K, Parissis JT, Farmakis D et al (2008) Effects of darbepoetin-alfa on quality of life and emotional stress in anemic patients with chronic heart failure. Eur J Cardiovascular Prev Rehabil 15:365-369

16. Parissis JT, Kourea K, Panou F et al (2008) Effect of darbepoetin alpha on right and left ventricular systolic and diastolic function in an anemic patients with chronic heart failure secondary to ischemic or idiopathic dilated cardiomyopathy. Am Heart J 155:751e1-751e7

17. Palazzuoli A, Silverberg DS, Iovine F et al (2006) Erythropoietin improves anemia, exercise tolerance, and renal function and reduces B-type natriuretic peptide and hospitalization in patients with heart failure and anemia. Am Heart J 152:1096e9-1096e15

18. Palazzuoli A, Silverberg DS, Iovine F et al (2007) Effects of $\beta$ erythropoietin treatment on left ventricular remodelling systolic function and B-type natriuretic peptide levels in patients with cardiorenal anemia syndrome. Am Heart J 645:e10-e15

19. Van Veldhuisen DJ, Dickstein K, Cohen-Solal A et al (2007) Randomized double blind placebo- controlled trial to evaluate the effect of two dosing regimens of darbepoetin alpha in patients with heart failure and anaemia. Eur Heart J 28:2208-2216

20. Ponikowski P, Anker SD, Szachniewicz J et al (2007) Effect of darbepoetin alpha on exercise tolerance in anemic patients with symptomatic chronic heart failure. J Am Coll Cardiol 49:753-762

21. European Society of Cardiology, Heart Failure Association of the ESC (HFA), European Society of Intensive Care Medicine (ESICM), Dickstein K, Cohen-Solal A, Filippatos G, McMurray JJ, Ponikowski P, Poole-Wilson PA, Strömberg A, van Veldhuisen DJ, Atar D, Hoes AW, Keren A, Mebazaa A, Nieminen M, Priori SG, Swedberg K, Vahanian A, Camm J, De Caterina R, Dean V, Dickstein K, Filippatos G, Funck-Brentano C, Hellemans I, Kristensen SD, McGregor K, Sechtem U, Silber S, Tendera M, Widimsky P, Zamorano JL, Tendera M, Auricchio A, Bax J, Böhm M, Corrà U, della Bella P, Elliott PM, Follath F, Gheorghiade M, Hasin Y, Hernborg A, Jaarsma T, Komajda M, Kornowski R, Piepoli M, Prendergast B, Tavazzi L, Vachiery JL, Verheugt FW, Zamorano JL, Zannad F (2008) ESC guidelines for the diagnosis and treatment of acute and chronic heart failure 2008: the Task Force for the diagnosis and treatment of acute and chronic heart failure 2008 of the European Society of Cardiology. Developed in collaboration with the Heart Failure Association of the ESC (HFA) and endorsed by the European Society of Intensive Care Medicine (ESICM). Eur J Heart Fail 29:23882442

22. Rostoker G, Andrivet P, Pham I, Griuncelli M, Adnot S (2007) A modified Cockcroft-Gault formula taking into account the body surface area gives a more accurate estimation of the glomerular filtration rate. J Nephrol 20:576-585

23. Ronco C, Haapio M, House AA, Anavekar N, Bellomo R (2008) Cardiorenal syndrome. J Am Coll Cardiol 52:1527-1529

24. Ghali JK, Anand IS, Abraham WT et al (2008) Randomized double-blind trial of darbepoietin alfa in patients with symptomatic heart failure and anemia. Circulation 117:526-535

25. Singh AK, Szczcech L, Tang KL et al (2006) Correction of anemia with epoietin alfa in chronic kidney disease. New Engl $\mathrm{J}$ Med 355:2085-2098

26. Drueke TB, Locatelli F, Clyne N et al (2006) Normalization of haemoglobin level in patients with chronic kidney disease and anemia. New Eng J Med 355:2071-2084

27. Anand SD, Comin Colet J, Filippatos G et al (2009) Ferric carboxymaltose in patients with heart failure and iron deficiency. New Engl J Med 361:2436-2448

28. Wright GL, Hanlon P, Amin K et al (2004) Erythropoietin receptor expression in adult rat cardiomyocytes is associated with an acute cardioprotective effect for recombinant erythropoietin during ischemia-reperfusion injury. FASEB J 25:285-291

29. Van der Meer P, Lipsic E, Henning RH et al (2005) Erythropoietin induces neovascularization and improves cardiac function in rats with heart failure after myocardial infarction. J Am Coll Cardiol 46:125-133

30. Lipsic E, Westenbrink BD, van der Meer P et al (2008) Low dose erythropoietin improves cardiac function in experimental heart failure without increasing haematocrit. Eur J Heart Fail 10:22-29 